\title{
Reformar a Administração Pública no novo mundo saído da guerra. Projeto nacional ou dinâmica global? (1950-1970)
}

\author{
Ana Carina Azevedo 1 \\ 1 Universidade Nova de Lisboa / Instituto de História Contemporânea, Faculdade de Ciências Sociais e Humanas, \\ Lisboa - Portugal
}

No final da década de 1960, Portugal iniciou um processo de Reforma da Administração Pública que pretendia
adequar as estruturas do Estado às novas lógicas do período e aos desafios por ele lançados. Entretanto, também
internacionalmente, as administrações públicas lutavam para melhorar seus níveis de eficiência para responder
às lógicas do desenvolvimento econômico e social. A importância desse desafio conduziu ao estabelecimento de
importantes redes de disseminação de princípios e práticas de Reforma da Administração Pública que incentivam
e suportam experiências por todo o mundo. Este artigo busca evidenciar a forma como o projeto de Reforma
Administrativa português foi devedor de impulsos internacionais variados, em um processo que se iniciou logo
após a Segunda Guerra Mundial e que seguiu linhas internacionais para cumprir objetivos nacionais. Palavras-chave: Portugal; Estado Novo; administração pública; desenvolvimento econômico e social; dinâmicas internacionais.

\section{Reformar la Administración Pública en el nuevo mundo posguerra. ¿Proyecto nacional o dinámica global? (1950-1970)}

A fines de la década de los sesenta Portugal emprendió un proceso de reforma de su administración pública que pretendía adecuar las estructuras del Estado a las nuevas lógicas y desafíos lanzados en ese período. El mismo esfuerzo se estaba realizando a nivel internacional para mejorar los niveles de eficiencia y responder a los propósitos generales de desarrollo económico y social. La importancia de dicho desafío condujo a la creación de importantes redes de diseminación de principios y prácticas de reforma de la administración pública, que incentivan y sustentan experiencias en todo el mundo. Este artículo pretende mostrar cómo el proyecto portugués de reforma administrativa fue deudor de esos diversos impulsos internacionales, en un proceso que se inició inmediatamente después de la Segunda Guerra Mundial y que siguió las recomendaciones internacionales para cumplir objetivos nacionales.

Palabras clave: Estado Nuevo; administración pública; desarrollo económico y social; dinámicas internacionales.

\section{Reforming Public Administration in the post-war world: Designing a national project or following global guidelines? (1950-1970)}

In the late 1960s, Portugal began a project for public administration reform in order to adapt the national structures to the new challenges of the decade. At the same time, internationally, governments were struggling to improve their levels of efficiency to respond better to the demands for economic and social development. These challenges led to the establishment of significant international networks responsible for the dissemination of principles and practices that encouraged and supported administrative reforms all over the world. This article intends to prove that the Portuguese project of administrative reform is a product of several international incentives. It also intends to show how this process began after the end of World War II and followed international guidelines to fulfil national objectives.

Keywords: Portugal; "Estado Novo"; public administration; economic and social development; international impulses. 


\section{INTRODUÇÃO}

No final da década de 1960, Portugal desenvolveu um projeto de reforma da Administração Pública que pretendia incidir sobre a situação econômica e social dos funcionários, as estruturas orgânicas da Administração, a qualidade das relações com o público e os métodos e processos de trabalho utilizados.

De fato, as deficiências da Administração Pública portuguesa haviam começado a ser reveladas no âmbito da gestão do Plano Marshall e por meio dos estudos preparatórios dos Planos de Fomento, aumentando a consciência acerca da necessidade de melhorar seu desempenho em uma época na qual o setor público se expandia e o volume de trabalho burocrático aumentava. Preconizado na Lei de Meios para 1962, o projeto é desenvolvido durante os estudos preparatórios do III Plano de Fomento, a partir dos quais é criado, no seio da Comissão Interministerial de Planeamento e Integração Econômica, o Grupo de Trabalho n. 14, responsável pelos estudos sobre a Reforma Administrativa. De seus trabalhos nasceria, em 1967, o Secretariado da Reforma Administrativa, organismo dependente da Presidência do Conselho que dirigiria os estudos e trabalhos tendentes à aplicação das reformas necessárias.

O projeto de Reforma Administrativa seria desenvolvido graças ao voluntarismo de alguns intervenientes, em sua maioria próximos da Presidência do Conselho e de outros organismos centrais do aparelho de Estado, e pretendia superar as debilidades apresentadas pela Administração Pública portuguesa. De fato, para manter o regime na época da vitória das democracias era necessário adaptar as estruturas do Estado às novas funções que este deveria desempenhar no que dizia respeito ao desenvolvimento econômico do país.

Entretanto, serão as lógicas que enquadraram o projeto português de Reforma Administrativa puramente nacionais? Serão originais seus métodos, objetivos e características? Ou existirão importantes impulsos internacionais dos quais a reforma portuguesa foi devedora? E, ainda, estaria o Portugal dos anos 1960 isolado quanto à necessidade de tornar a Administração Pública mais eficiente, ou seria esta uma preocupação global?

A bibliografia referente ao estudo sobre os processos de Reforma Administrativa ocorridos durante o Estado Novo português é escassa e não aborda as conexões internacionais aqui consideradas. Nesse quadro, este artigo busca defender que o processo de Reforma Administrativa desenvolvido em Portugal, grosso modo entre 1967 e 1972/73, não é original, apesar de apresentar algumas especificidades, integrando-se em um movimento global de reforma das administrações públicas que começa anteriomente e tem lugar não apenas na Europa, mas também na América Latina, Ásia e África. Almeja salientar a forma como Portugal entrou em contato, de forma direta e indireta, com organismos internacionais que tinham como função a difusão de uma nova lógica para as administrações públicas mundiais. Por último, pretende evidenciar semelhanças não só cronológicas, mas também em termos de objetivos e características, entre o processo de reforma da Administração Pública portuguesa e outros projetos desenvolvidos internacionalmente.

\section{A NECESSIDADE DE UMA NOVA ADMINISTRAÇÃO PÚBLICA CENTRADA NO DESENVOLVIMENTO}

No final da Segunda Guerra Mundial, a Administração Pública enfrentava desafios globais. Por um lado, os países diretamente atingidos pelo recrutamento militar e que já haviam sentido a necessidade de formar rapidamente novos funcionários durante o conflito, debatiam-se agora com a necessidade de readaptar aqueles que reingressavam nos serviços do Estado. Por outro, a necessidade de racionalizar 
o aparelho de Estado, tornando-o menos dispendioso, apresentava-se como um problema em nível internacional (Talloen, 1957). E, simultaneamente, as transformações sociais e econômicas que surgiam por todo o mundo conduziam ao desenvolvimento de um novo papel do Estado na sociedade, ao qual passariam a ser atribuídas novas funções enquanto promotor do desenvolvimento econômico e do bem-estar social que implicavam um maior nível de intervencionismo.

De fato, o mundo havia mudado após a Segunda Guerra Mundial e essas mudanças teriam reflexos diretos no papel e nas funções atribuídas ao Estado. Na Europa, a reconstrução e reconstituição econômica do continente necessitava basear-se em uma função pública eficiente, mais desenvolvida e com novas funções nos planos econômico e social. Na África e na Ásia, a vaga de independências do pós-guerra fizera nascer novos Estados, nos quais a Administração Pública teria de ser reorganizada de acordo com novas lógicas. Na América Latina, os Estados Unidos da América (EUA) entendiam a necessidade do desenvolvimento econômico e social, assente em administrações públicas sólidas, como um elemento essencial para o evitar da disseminação de doutrinas socialistas. Em qualquer dos casos, uma Administração Pública eficaz era considerada o garante do desenvolvimento econômico e do bem-estar social, essenciais para a manutenção da paz e a defesa da democracia (cf. Caiden, 1973; Otenyo \& Lind, 2006; Phillips, 1963).

Simultaneamente a uma alteração do papel do Estado na sociedade e ao consequente alargamento de suas funções, aprofunda-se a consciência da inadequação das administrações públicas que se mantinham, de forma geral, baseadas em métodos de trabalho tradicionais e rotineiros, apresentando um baixo nível de eficiência e de produtividade. Além disso, a função pública lutava em alguns países contra uma perigosa fuga de quadros qualificados para o setor privado, decorrente das diferenças salariais apresentadas entre os dois setores e do aumento das regalias atribuídas pelas empresas privadas. Essas regalias incidiam particularmente no nível dos apoios a doença, invalidez e aposentação e, ainda, no que diz respeito a gratificações e ao pagamento de horas extras (cf. Gonçalves, 1972; Salgueiro, 1971) Assim, o desenvolvimento da Administração Pública passaria a ser entendido, sobretudo a partir da década de 1950, como uma preocupação global, independentemente da natureza dos regimes políticos e das diferenças econômicas e sociais entre países (United Nations Organization [UNO], 1967).

Em nível teórico, o desenvolvimento das Ciências Administrativas acompanhava essa problemática alertando para a necessidade de modernização da estrutura e dos métodos de trabalho das administrações públicas segundo modelos científicos de organização do trabalho. Alertava, ainda, para a necessidade de apostar na formação dos funcionários, de definir de forma clara seus direitos e deveres e de lhes serem atribuídos benefícios equivalentes àqueles que eram proporcionados pelas empresas privadas, de modo a evitar a fuga de trabalhadores qualificados (Gonçalves, 1972).

Essa consciência sobre a necessidade de renovar as administrações públicas, tornando-as mais eficientes, e de rever o papel e perfil dos Estados e seu nível de intervencionismo na sociedade e na economia se encontrava relacionado com o desenvolvimento do conceito de "administração para o desenvolvimento". De fato, o crescimento econômico dos "Trinta Gloriosos"1 necessitava estar ancorado em estruturas administrativas preparadas para responder aos desafios do desenvolvimento, sendo o

\footnotetext{
${ }^{1}$ Designam-se "Trinta Gloriosos" os anos que mediaram o final da Segunda Guerra Mundial e a primeira metade dos anos 1970, sendo caracterizados por um crescimento econômico sem precedentes no século XX. A época é, também, apelidada de "Era Dourada", segundo a definição de Eric Hobsbawn.
} 
Estado diretamente responsável por promover as condições e estratégias necessárias à sua prossecução. Na Europa, quer o Programa de Reconstrução e Reconstituição Econômica desenvolvido pelos EUA, quer os planos nacionais de fomento econômico, necessitavam de uma estrutura administrativa capaz, que apresentasse eficiência e rapidez e que estivesse baseada em um corpo de funcionários devidamente formado. Era necessário estender as lógicas da produtividade à Administração Pública, renovar estruturas, organismos e métodos de trabalho e garantir que o setor público mantinha capacidade de atração dos melhores funcionários. Por seu lado, nos países do Sul, as consequências da Segunda Guerra Mundial, a vaga de descolonizações e as lógicas da Guerra Fria conduziriam à necessidade de criar administrações públicas desenvolvidas e organizadas, dotadas de funcionários capazes, que pudessem gizar projetos de desenvolvimento sustentado, normalizar os novos Estados, melhorar o nível de vida das populações e garantir a paz (International Institute of Administrative Sciences [IIAS], 1971).

A Administração para o Desenvolvimento passou, assim, a ser um conceito conhecido quase de modo global. Englobava as reformas administrativas necessárias para munir as administrações públicas das condições de que careciam para promover políticas e estratégias de desenvolvimento econômico e social e assegurar apoio administrativo ao planeamento econômico e ao desenvolvimento social (Gant, 2006).

\section{A EXPANSÃO INTERNACIONAL DA "ADMINISTRAÇ̃̃O PARA O DESENVOLVIMENTO"}

As novas funções atribuídas, de modo quase global, aos Estados e a importância da Administração para o Desenvolvimento fizeram com que a problemática da reforma das administrações públicas fosse largamente difundida por organismos internacionais e programas de assistência técnica.

A Organização das Nações Unidas (ONU) foi uma das entidades que mais contribuíram para a renovação das administrações públicas em nível global por meio de um programa estruturado de assistência técnica, chamando a atenção para a necessidade da criação de administrações públicas sólidas e eficientes como sustentáculos do progresso econômico e social. De fato, a Carta das Nações Unidas (Organização das Nações Unidas [ONU], 1945), apresentava como objetivo, no artigo 55, a promoção das condições necessárias para o desenvolvimento econômico e social mundial, sendo que o aperfeiçoamento da Administração Pública em nível global era entendido como um dos fatores que possibilitariam esse mesmo desenvolvimento. Como tal, o primeiro programa da ONU nesse campo teria início a partir da primeira sessão da Assembleia Geral dedicada à promoção do bem-estar social. A necessidade de formação de pessoal especializado nessas matérias foi reconhecida pouco depois, pela Resolução n. 58 (I) da Assembleia Geral, de dezembro de 1946, que defendia a criação de um programa de formação para funcionários ligados aos campos do bem-estar social no setor público (UNO, 1967).

Dois anos depois, a ONU iniciou um programa de assistência técnica dedicado à Administração Pública, cujas operações tiveram efetivamente início em 1950, com a atribuição das primeiras bolsas e o envio dos primeiros especialistas. O programa de concessão de bolsas foi financiado pela Assembleia Geral da ONU e dava inicialmente prioridade à formação de funcionários civis intermédios dos Estados-membros. Os fundos atribuídos pelas bolsas deveriam ser utilizados na organização e participação em seminários relativos aos problemas da Administração Pública, bem como no desenvolvimento ou melhoria de instituições nacionais que ofereciam cursos sobre as mesmas temáticas (UNO, 1951). 
A ONU reconhecia a urgência de colocar à disposição dos Estados-membros os métodos administrativos mais eficientes, garantindo efetivas transferências de conhecimento e assistência técnica, de modo a assegurar o desenvolvimento sustentado e a difusão das Ciências Administrativas no mundo (UNO, 1948). Em 1949, 24 países solicitariam assistência técnica da ONU nos domínios da Administração Pública, por meio do pedido de 120 bolsas, das quais 38 foram concedidas, tendo sido iniciadas no ano seguinte (UNO, 1948). Teve início, também, uma colaboração com o Instituto Internacional de Ciências Administrativas (IICA), que resultou na publicação de uma série de monografias e de estudos comparativos relativos à Administração Pública que foram usados em projetos de formação em todo o mundo, inclusive naqueles que não eram diretamente patrocinados pela ONU (UNO, 1948).

Tendo tido início pelas questões da formação de funcionários, o programa de assistência técnica amplia a sua ação se tornando um projeto mais abrangente de apoio aos governos no âmbito da reforma das administrações públicas, compreendendo três níveis de ação. Por um lado, a concessão de assistência técnica, após solicitação dos governos, que incluía atividades de formação realizadas por meio de serviços de peritos; concessão de bolsas; criação ou apoio de institutos de formação; realização de seminários, conferências e grupos de trabalho; e publicações técnicas. Por outro, a compilação, análise e troca de informação técnica relativa à Administração Pública feita em colaboração com o IICA e outros organismos; e, por último, a assistência técnica aos governos, de modo a promover a constituição de uma administração sólida e articulada com o desenvolvimento econômico e social (UNO, 1953). A importância dos trabalhos desenvolvidos durante a década de 1950 conduziu à prossecução do programa de assistência técnica da ONU em matéria de Administração Pública na década seguinte, designada como Década de Desenvolvimento das Nações Unidas.

Nessa década, os tópicos mais focados no âmbito da assistência técnica em Administração Pública da ONU se prendiam principalmente com a implementação de princípios de Organização e Métodos (O\&M) e de simplificação do trabalho, sendo enfatizada a importância da criação de serviços centrais de O\&M, bem como de gabinetes centrais de planeamento administrativo diretamente ligados ao serviço responsável pelo planeamento econômico. No que a formação dos funcionários diz respeito, o programa de concessão de bolsas passaria a privilegiar a participação de funcionários com cargos de chefia, como forma de aumentar as possibilidades de efetiva implementação dos princípios e métodos apresentados (UNO, 1951).

O programa de assistência técnica da ONU apresenta, de fato, um caráter quase global. Entretanto, é preciso notar que, nos anos 1960, as relações entre Portugal e a ONU eram tensas (Pereira, 2005). Como se explicam, assim, as semelhanças encontradas entre o processo de Reforma Administrativa encetado em Portugal no final da década e as experiências internacionais apoiadas pela ONU? A participação de Portugal em organismos como a Organização para a Cooperação e Desenvolvimento Econômico (OCDE), a Agência Europeia de Produtividade (AEP) e instituições nacionais de países europeus, tendo possibilitado parte das ações de formação e missões de estudo integradas por Portugal, seria o veículo que colocaria o país em contato com este movimento internacional. Porém, também o IICA, financiado pela ONU e cuja revista era utilizada como órgão de divulgação de seus programas de assistência técnica, teria tido um papel bastante interessante no processo. Por meio das publicações e reuniões científicas do IICA, Portugal recebia a informação técnica difundida pela ONU, mantinha-se ao corrente da evolução internacional e estabelecia contato com técnicos estrangeiros, encontrando- 
se ligado a uma verdadeira rede internacional em matéria de Administração Pública que influenciou os processos de Reforma Administrativa por todo o mundo (Hosch, 1964).

O IICA havia sido criado no início da década de 1930, na sequência da evolução da Comissão Internacional Permanente dos Congressos de Ciências Administrativas. Essa comissão, nascida após o primeiro Congresso Internacional de Ciências Administrativas, realizado em 1910, em Bruxelas, tinha por objetivo a preparação de congressos futuros e, em seu início, era composta por representantes de 22 países, entre os quais Portugal (Fisch, 2005). Posteriormente, no início da década de 1930, a Comissão Internacional Permanente dos Congressos de Ciências Administrativas seria transformada em um organismo mais estável, que tomaria o nome de IICA.

Portugal seria um dos primeiros países a apresentar uma seção nacional dessa Comissão Internacional e acabou por aderir ao instituto logo após sua criação. Os congressos, as mesas-redondas, as reuniões científicas e as publicações do IICA foram responsáveis pela criação de importantes redes de partilha de conhecimento no âmbito das Ciências Administrativas. Eles colocavam em contato os técnicos pertencentes às seções nacionais do organismo e outros estudiosos da Administração Pública e divulgavam os trabalhos teóricos e as experiências nacionais de Reforma Administrativa colocadas em prática nas mais diversas zonas do globo. A colaboração portuguesa com o instituto possibilitou, além dos contatos internacionais anteriormente referidos, que o país usufruísse de uma série de ações de formação destinadas principalmente aos funcionários dos escalões mais elevados da Administração Pública. Após a Segunda Guerra Mundial, a cooperação portuguesa com o IICA se aprofundou, iniciando-se uma relação mais próxima na qual se encontram integrados alguns dos principais intervenientes da Reforma Administrativa em Portugal.

\section{PORTUGAL E O MOVIMENTO INTERNACIONAL DE REFORMA DAS ADMINISTRAÇÕES PÚBLICAS}

As lógicas internacionais anteriormente descritas constituíram apenas uma pequena parte do esforço desenvolvido após a Segunda Guerra Mundial, com o intuito de melhorar globalmente as práticas administrativas (Israel, 1957), e que foi apoiado por organismos como a ONU, a Agência dos Estados Unidos para o Desenvolvimento Internacional, a Organização dos Estados Americanos, a Fundação Ford e a Comissão Econômica para a América Latina (Phillips, 1963). Assim, a Reforma Administrativa, apesar de constituir uma realização nacional, tem uma profunda conotação internacional. Portanto, não é de estranhar que, apesar dos projetos colocados em prática nos vários países se encontrarem integrados em suas próprias características e ajustados às suas necessidades, existam vários traços em comum nos objetivos, métodos e conteúdos evidenciados internacionalmente.

Essa realidade também é visível em Portugal. Apesar de evidenciar algum atraso relativamente a algumas realidades internacionais, a Reforma Administrativa projetada na segunda metade dos anos 1960 e na primeira metade da década seguinte, não obstante integrar as lógicas nacionais da altura, evidencia semelhanças com a realidade internacional. Por um lado, apresenta clara ligação com os princípios e métodos científicos de organização do trabalho administrativo difundidos no âmbito da participação de Portugal no Plano Marshall, no qual o Estado é o principal beneficiário (Rollo, 2007), e nas iniciativas de formação organizadas pela OCDE e pela AEP, sem esquecer o papel dos consultores internacionais em organização ou o contributo das iniciativas de organismos como o Instituto Nacional de Investigação Industrial (INII) (Azevedo, 2014). Por outro, também se tornam visíveis algumas influências do programa de assistência técnica da ONU, bem como semelhanças com 
processos de Reforma Administrativa realizados um pouco por todo o mundo, nomeadamente em zonas que escapavam à influência do Plano Marshall, mas que foram beneficiadas, de forma direta ou indireta, pela assistência técnica da $\mathrm{ONU}^{2}$.

Essa relação é visível no nível dos objetivos, dos agentes, da cronologia e das características que o processo de Reforma Administrativa dos anos 1960 apresentou no país. No que aos objetivos diz respeito, e não obstante cada país apresentar algumas especificidades em seus propósitos, os processos de Reforma Administrativa encetados na época apresentam intenções semelhantes, como se tornou visível nas seções anteriores. A necessidade de adaptar o funcionalismo público aos desafios decorrentes do novo papel do Estado, enquanto promotor do desenvolvimento econômico e social, apresentavase como o objetivo principal das Reformas Administrativas. Em Portugal, esse processo é fruto de alguns voluntarismos cujos intervenientes, em sua maioria, são tocados direta ou indiretamente por organismos e redes que se dedicavam à difusão dos métodos que permitiam melhorar a eficiência da Administração Pública.

Essa relação é bastante explícita no que diz respeito ao IICA. Marcello Caetano, professor de Direito Administrativo, um dos principais responsáveis pela Reforma Administrativa da década de 1930, pelo Código Administrativo de 1940 e apoiante da reforma iniciada em 1967, foi um dos principais interlocutores entre Portugal e o IICA, sendo presença habitual nas reuniões do organismo e tendo sido vice-presidente dele na década de 1940. António Pedrosa Pires de Lima, diretor-geral da Administração Política e Civil e autor de várias publicações referentes às problemáticas da Administração Pública, faria parte do Comitê Científico do Instituto; Aureliano Felismino, diretor-geral da Contabilidade Pública e responsável pelo Gabinete de Estudos António José Malheiro, organismo no qual foram desenvolvidos importantes estudos e experiências sobre racionalização da Administração Pública, seria membro do Comitê de Práticas Administrativas. Diogo de Paiva Brandão, secretário-geral da Presidência do Conselho, organismo que superintendia a Reforma Administrativa, é presença corrente nos congressos do IICA e membro da seção portuguesa dele, tornado Instituto Português de Ciências Administrativas (IPCA) em 1968. Duarte Nuno de Vasconcellos, membro da delegação portuguesa ao Congresso Internacional de Ciências Administrativas de 1971, realizado em Roma, e especializado em O\&M pela Escola Nacional de Administração Pública de Espanha, desempenharia o papel de monitor em ações de formação organizadas pelo Secretariado da Reforma Administrativa ${ }^{3}$.

Verifica-se, assim, que alguns dos mais importantes intervenientes na Reforma Administrativa em Portugal, quer por fazerem parte dos serviços responsáveis por ela, quer por apresentarem cargos superiores em organismos que apostaram em seu estudo e aplicação, encontravam-se ligados às iniciativas do IICA tendo, igualmente, por essa via, acesso à informação técnica e experiências internacionais suportadas pela ONU. Além disso, a influência de organismos como a OCDE e a AEP na formação de técnicos e na difusão de métodos científicos de organização dos escritórios e do trabalho administrativo é, igualmente, bastante relevante. É, de fato, bastante visível a existência em Portugal de um conjunto de indivíduos profundamente ligados à Administração Pública, pelos cargos governativos e técnicos que desempenham, que constituíram uma plataforma de apoio para

\footnotetext{
${ }^{2}$ Essas influências podem ser constatadas nos artigos referentes às reformas administrativas desenvolvidas em diversos países e que se encontram na International Review of Administrative Sciences, revista do IICA.

${ }^{3}$ Informação compilada nos 17 números da revista Ciências Administrativas, Boletim do Instituto Português de Ciências Administrativas, entre os anos de 1969 e 1973.
} 
a implementação de tentativas de Reforma Administrativa. Sua consciência sobre a necessidade de transformar a administração fez com que aproveitassem as possibilidades de formação e transferência de conhecimento proporcionadas pelas referidas redes internacionais, para tentar implementar em Portugal as mudanças que consideravam necessárias. As lógicas internacionais que impeliam a transformação da Administração Pública e o empenho, internacionalização e consciencialização desses indivíduos se conjugaram, assim, no sentido de possibilitar tentativas de modernização administrativa.

Atentando nas ações de formação desenvolvidas em Portugal que incidiram sobre problemáticas relacionadas com a melhoria da eficiência da Administração Pública se verifica que, nos primeiros anos, estas decorreram de iniciativas da OCDE e da AEP, apresentando grande presença de monitores estrangeiros. Posteriormente, torna-se visível um papel cada vez maior de monitores portugueses, muitos deles formados anos antes no exterior (Azevedo, 2014). E, também, sob a iniciativa do IICA e do IPCA foram desenvolvidas ações de formação que contaram com a presença de monitores estrangeiros e foi permitida a alguns técnicos nacionais a participação em formações no estrangeiro. Assim, os atores que viriam a influir nas mudanças que deveriam ser efetuadas na Administração Pública entravam em contato, durante sua formação, com os princípios e métodos tendentes à melhoria da eficiência dela que eram difundidos por organismos e monitores estrangeiros, integrados em redes internacionais de transferência de conhecimento.

No que à cronologia diz respeito, o movimento pela reforma das administrações públicas que tem lugar no terceiro quartel do século XX se inicia, como testemunha o desenvolvimento do programa de assistência técnica da ONU, ainda no final da década de 1940. Em Portugal, esse processo é mais tardio. Não obstante algumas reformas parciais e desarticuladas que têm lugar, sobretudo, desde a década de 1950, o estudo mais sistemático sobre o tema decorre dos trabalhos preparatórios do III Plano de Fomento, sendo materializado apenas em 1967, com a criação do Secretariado da Reforma Administrativa. Na década anterior, as diligências administrativas incluídas nas lógicas do Plano Marshall já haviam alertado para o baixo nível de eficiência, organização e capacidade de resposta da Administração Pública nacional. No entanto, as necessidades relacionadas com o planeamento e a execução dos Planos de Fomento cimentaram essa consciência, em uma época na qual o Estado português se via compelido a abarcar novas funções relativas ao desenvolvimento do país, tornandose mais interventivo em nível econômico e social (cf. Caiden, 1973; Passos, 1991).

Entretanto, nem todos os países iniciaram seus processos de Reforma Administrativa na viragem dos anos 1940 para a década de 1950. Na verdade, o final dos anos 1950 e, sobretudo, toda a década de 1960, foram a época de maior expansão desses processos. Como exemplo, na Espanha as primeiras tentativas de modernização da Administração Pública foram, tal como em Portugal, encetadas nos anos 1960, pautando-se pela introdução de novas técnicas oriundas do setor privado na Administração Central e na gestão dos funcionários, bem como no nível do orçamento e do planeamento econômico (Alba, 2008). Essa transformação se deveu às mudanças econômicas ocorridas durante a década de 1960, que alertaram para a necessidade de uma Administração Pública menos legalista e mais orientada às técnicas de gestão, de modo a conseguir gerir o aumento do intervencionismo estatal na sociedade e a expansão do corpo de funcionários. Assim, a partir de 1964, sob a égide do Ministro da Presidência, são feitas reformas estruturais e legais, coordenadas com as lógicas do planeamento econômico, que permitiram uma modernização real de alguns órgãos do Estado sem colocar em causa a natureza do regime (Alba \& Navarro, 2011). 
Contudo, também na França, os anos 1960 marcam uma mudança nas lógicas da Administração Pública no que diz respeito à aplicação de métodos de gestão e organização, afirmando-se o princípio de que não só a Administração Pública poderia ser avaliada em termos de eficiência, mas deveria melhorar a produtividade e racionalizar os métodos de trabalho (Chevalier, 2006). A Holanda e a Alemanha apresentam cronologias similares. Na Holanda, os anos 1960 são marcados pelo desenvolvimento das Ciências Administrativas, fruto da expansão de um Estado Social que necessitava de um suporte científico para sua racionalização (Kickert, 2006) e conduzia a um crescimento das funções públicas que implicava planeamento e estratégias políticas (Kickert, 2006). A mesma realidade é evidenciada na Alemanha, com o surgimento de reformas administrativas que tendiam a adequar o aparelho de Estado às lógicas do Estado Social e a modernizar o setor público. Mas também alguns dos países do Sul apresentariam experiências de reforma na mesma época. A Colômbia, por exemplo, inicia em 1958 um processo de Reforma Administrativa que se desenvolveria durante a década de 1960 (Groves, 1974) E, nas mesmas décadas, decorriam projetos similares em países tão distintos como a Jordânia, o Vietnã e a Índia, apenas para citar alguns exemplos.

Por último, não obstante as especificidades de cada caso nacional, as principais características das reformas administrativas concretizadas ou estudadas internacionalmente são relativamente semelhantes, sendo também aquelas que se tornam evidentes no caso português. Em Portugal, a Reforma Administrativa iniciada nos anos 1960 se desenvolveu em torno de quatro eixos de ação: a situação dos funcionários públicos; as estruturas orgânicas da administração; as relações com o público; e as operações desempenhadas pelos serviços (Secretariado da Reforma Administrativa, 1968). Analisando quer os objetivos do programa de assistência técnica da ONU, quer as publicações do IICA e alguns projetos internacionais, verifica-se que esses eixos também estruturam, em grande medida, os processos de reforma desenvolvidos em outros países.

No que ao primeiro eixo diz respeito, a necessidade de melhorar a situação econômica e o bem-estar social dos funcionários públicos se encontra presente no âmbito do programa de assistência técnica da ONU desde seus primeiros anos. Em 1951, o relatório do Comitê Especial sobre os Problemas da Administração Pública alertaria para a necessidade de oferecer melhores condições e mais altos salários aos servidores públicos, de modo que fosse possível manter no serviço do Estado funcionários com experiência nos campos do desenvolvimento e atrair um número suficiente de técnicos de elevada competência profissional. No caso português, o baixo nível remuneratório da função pública aliado à inflação constituíam fatores que conduziam à procura de um segundo emprego e à aceitação de fontes de rendimento irregulares por parte dos funcionários públicos, em uma lógica que não só era prejudicial para sua qualidade de vida, mas também implicava menor dedicação à função pública. Além disso, as linhas orientadoras da reforma defendiam a necessidade de dar atenção aos apoios sociais dos funcionários públicos em termos de auxílio à doença ou reforma, regalias que haviam sido melhoradas no setor privado (UNO, 1951).

Essa preocupação é, de fato, um dos aspetos mais levados em conta internacionalmente. Na Europa, os processos de Reforma Administrativa de países como França, Malta, Itália ou Dinamarca apresentam como prioridade a melhoria das condições e dos horários de trabalho; o estudo dos problemas de recrutamento, promoção e classificação dos funcionários; e o estudo de seus níveis salariais, sem esquecer as questões ligadas à formação (Alhaique, 1957; Godchot, 1970; Henares, 1961; Meyer, 1960). Entretanto, também na América Latina e na Ásia essas questões fariam parte dos pilares das reformas administrativas que decorriam na época. Na Jordânia, a reforma da Administração Pública 
apresentava como ponto essencial o estabelecimento de novas regras relativas ao funcionalismo, incidindo particularmente na criação de uma nova escala salarial (IIAS, 1958). A Argentina, a Costa Rica, El Salvador, a Venezuela e o México, cujos processos de Reforma Administrativa eram bastante devedores da assistência técnica da ONU e dos EUA, apresentavam, igualmente, uma grande atenção ao fator humano. Demonstravam preocupação com a reestruturação das carreiras administrativas, o estabelecimento de novas regras de recrutamento, a revisão dos programas de formação e exibiam uma atenção renovada sobre os problemas salariais, o estatuto da função pública e a planificação dos recursos humanos (Arias, 1957; Brewer-Carias, 1970, 1972; Castro, 1974).

Contudo, o aspeto central das reformas acabava por estar relacionado com as estruturas orgânicas da administração, sendo que Portugal apostou, de fato, na reorganização e reestruturação de organismos e serviços públicos, tentando atribuir-lhes maior grau de eficiência e racionalidade. Também internacionalmente esse era considerado um elemento essencial nos processos de Reforma Administrativa, sendo defendido que os principais problemas da Administração Pública se encontravam relacionados com a falta de coordenação entre os programas administrativos e os departamentos, ministérios e serviços existentes; bem como com a utilização de métodos e circuitos de trabalho sem operacionalidade.

Internacionalmente, considerava-se que as estruturas da Administração Pública, apesar de deverem ser adequadas à realidade nacional, deveriam manter-se simples, apresentando um número de serviços o mais reduzido possível, com funções claramente definidas. Era, assim, crucial reorganizar as estruturas administrativas e, se necessário, estabelecer novos departamentos, em um processo que deveria ser acompanhado por um secretariado ou conselho para a Reforma Administrativa colocado na dependência do chefe do Executivo (UNO, 1951).

De fato, a ligação entre esse organismo central responsável pela reforma da Administração Pública e o chefe do Executivo foi característica dos processos de reforma em nível internacional, sendo também defendida pelo programa de assistência técnica da ONU. Em Portugal, o Secretariado da Reforma Administrativa seria criado junto da Presidência do Conselho, tal como se verificaria nos casos espanhol, italiano, argentino, venezuelano, mexicano (Alhaique, 1957; Brewer-Carias, 1970; Castro, 1974; Pozas, 1957) e colombiano (Groves, 1974), entre outros. Esse organismo central de estudo e planificação, junto com os núcleos de O\&M criados nos vários departamentos governamentais, contribuía para a reestruturação de ministérios, serviços, departamentos e outros organismos estatais, cuja reorganização era entendida como essencial para melhorar a eficiência da Administração Pública.

Da mesma forma, a ligação do Ministério das Finanças à Reforma Administrativa encontrada em Portugal quer na reforma da década de 1930, quer a partir da criação do Gabinete de Estudos António José Malheiros (Azevedo, 2017), também é uma característica internacional, pois, na nova lógica da administração para o desenvolvimento surgiu a necessidade de um Ministério das Finanças mais interventivo e com maior capacidade técnica.

As operações e os métodos de trabalho desempenhados pelos serviços públicos apresentavam, igualmente, uma importância relevante em nível internacional. Aliada à reorganização de organismos públicos se encontrava a implementação de novos procedimentos e métodos administrativos, baseados no estudo dos circuitos de trabalho. Em alguns países, como Portugal, instalam-se gabinetes de O\&M tendo por objetivo a promoção da uniformidade organizativa, administrativa e processual para todos os serviços; a melhoria da qualidade das operações do governo por meio de serviços especializados de organização e administração; a promoção de economias de escala; e o auxílio aos departamentos 
existentes, retirando-lhes o esforço acrescido que significava exercer funções de organização em suas operações (UNO, 1951).

De fato, e na esteira das recomendações da ONU, a utilização de núcleos de O\&M é uma realidade comum aos países que encetam processos de reforma, quer estes desempenhem uma ação de conjunto sob a dependência de um organismo central ou encontrem-se dispersos pelos vários órgãos do Estado. A necessidade de simplificar métodos e procedimentos de trabalho, de racionalizar circuitos de documentação e de implementar a mecanização e a automação está presente nas reformas administrativas encetadas por todo o mundo (cf. Brewer-Carias 1970; Castro, 1974; François, 1970; Godchot, 1970; Koch, 1967; Laberge, 1960; Langrod, 1964; Meyer, 1960; Uotila, 1961; Wurmser, 1957).

\section{CONCLUSÃO}

A bibliografia portuguesa ou referente a Portugal que incide sobre as problemáticas da modernização da Administração Pública durante o Estado Novo é bastante escassa. Mais ainda, esses estudos raramente escapam a uma lógica de análise nacional, ligada aos pressupostos políticos e econômicos do regime. Este artigo busca contribuir para a atribuição de maior abrangência à análise relativa à modernização administrativa nas décadas anteriores à revolução que, em 1974, instauraria a democracia em Portugal. Considerando a forma como em Portugal se refletem impulsos internacionais no nível dos estudos administrativos, almejou-se inserir na equação do processo de modernização administrativa o papel da abertura do país ao exterior e da internacionalização de uma geração de quadros.

De fato, atentando ao modo como o processo de Reforma Administrativa encetado no final da década de 1960 foi apresentado pelo Estado Novo, este pode ser entendido facilmente como um projeto puramente nacional, não obstante os visíveis impactos internacionais no nível da formação de funcionários e técnicos. Entretanto, analisando a realidade internacional, verifica-se que a reforma iniciada em Portugal não se apresenta como original, seguindo, em grande medida, as lógicas que vinham sendo largamente difundidas internacionalmente desde o final da Segunda Guerra Mundial. Apesar do ligeiro atraso, a Reforma Administrativa portuguesa apresenta características, objetivos e metodologias semelhantes à realidade internacional e, no nível de seus agentes, o papel da internacionalização e do contato direto ou indireto com os organismos que defendiam a necessidade de melhorar a eficiência das administrações públicas é evidente.

Não obstante a natureza do regime, mas sem a colocar em causa, Portugal é impelido, após a Segunda Guerra Mundial, a refletir sobre seu próprio processo de desenvolvimento econômico, sendo o Estado chamado a apresentar um papel mais interventivo em prol do desenvolvimento. As diligências necessárias à gestão do Plano Marshall e as lógicas decorrentes do planeamento econômico corporizadas nos Planos de Fomento evidenciam uma Administração Pública pouco eficiente, utilizando métodos e processos de trabalho rotineiros e pouco racionais, composta por funcionários debilmente formados que, cada vez mais, viam-se atraídos pelas melhores condições proporcionadas pelo setor privado. O desenvolvimento econômico do país dependia, assim, de uma efetiva reforma da Administração Pública.

Paralelamente a esse reconhecimento, Portugal havia encetado maior abertura ao exterior. O Programa de Assistência Técnica e Produtividade havia colocado o país em contato com organismos como a OCDE e a AEP. Dessa forma, Portugal integra, sobretudo como beneficiário, as redes internacionais de transferência de conhecimento criadas por esses organismos, bem como aquelas 
que derivam da colaboração portuguesa com o IICA e que lhe permitem, de modo indireto, entrar em contato com a informação técnica e as experiências internacionais decorrentes dos programas de assistência técnica da ONU.

Também no nível das características da Reforma Administrativa portuguesa, os impactos internacionais são evidentes. Os eixos de ação sob os quais ela decorre também são aqueles que, não obstante as especificidades de cada país, mais se verificam internacionalmente, sucedendo o mesmo com suas principais características. De fato, ao confrontar as fontes e bibliografia internacionais e, sobretudo, os artigos publicados na International Review of Administrative Sciences, onde os vários processos de reforma vão sendo relatados, tal realidade se torna bastante visível. A prioridade atribuída internacionalmente à situação econômica e social dos funcionários públicos, às estruturas orgânicas da Administração, às relações com o público e às operações desempenhadas pelos serviços é bastante evidente. O projeto de Reforma Administrativa português não é, assim, original, mas devedor de lógicas e contatos internacionais.

Nesse ponto, é necessário não esquecer a importância de um conjunto de agentes que se afirmaram como a plataforma de apoio aos processos de reforma da Administração Pública. Fortemente internacionalizados, conscientes da necessidade de modernização administrativa nacional e presença recorrente nos organismos internacionais ligados ao estudo das ciências administrativas, constituíram os elementos de contato entre as referidas redes internacionais e a Administração Pública portuguesa.

No entanto, apesar de absorver as experiências internacionais e seguir as principais linhas desenvolvidas no exterior, a Reforma Administrativa portuguesa se submete às prioridades do regime. Enquanto internacionalmente a melhoria do desempenho das administrações públicas era teoricamente apresentada como fator de fortalecimento dos regimes democráticos, Portugal necessitava de uma administração eficiente para manter a ditadura e os territórios ultramarinos. Baseado em um conjunto de quadros que compreende e sustenta a necessidade de melhorar a máquina administrativa do Estado, o processo de reforma da Administração Pública portuguesa projetado na década de 1960 e início dos anos 1970 utiliza, assim, linhas internacionais para cumprir objetivos nacionais, aliando o desenvolvimento econômico e social à manutenção do regime. 


\section{REFERÊNCIAS}

Alba, C. (2008). Bureaucratic politics in Spain. A long-lasting tradition. In G. Peters, \& J. Pierre (Orgs.), Politicians, bureaucrats and administrative reform (pp. 89-100). New York, NY: Routledge.

Alba, C., \& Navarro, C. (2011). Administrative tradition and reforms in Spain: adaptation versus innovation. Public Administration, 89(3), 783-800.

Alhaique, C. (1957). La productivité dans l'Administration Publique en Italie. International Review of Administrative Sciences, 23(4), 497-502.

Arias, J. C. (1957). Experiencia argentina en organización y métodos para el mejoramiento de la administración pública. International Review of Administrative Sciences, 23(2), 185-199.

Azevedo, A. C. (2014). A organização científica do trabalho em Portugal após a II Guerra Mundial: 1945-1974 (Tese de Doutorado). Universidade Nova de Lisboa, Lisboa, Portugal.

Azevedo, A. C. (2017). A organização científica do trabalho administrativo em Portugal: o Ministério das Finanças enquanto "laboratório administrativo"? (1945-1974). Estudos do CEPE, 2017(45), 92-108.

Brewer-Carias, A. (1970). Reforma Administrativa y desarrollo económico y social en Venezuela. International Review of Administrative Sciences, 36(1), 34-46.

Brewer-Carias, A. (1972). Las propuestas de Reforma de la Administración Pública venezolana (1972). International Review of Administrative Sciences, 38(3), 252-261.

Caiden, G. E. (1973). Development, administrative capacity and administrative reform. International Review of Administrative Sciences, 39(4), 327-344.

Castro, A. (1974). La Reforma Administrativa en México (estudio de un caso). International Review of Administrative Sciences, 40(1), 58-74.

Chevalier, J. (2006). Changing European States, changing Public Administration: Public Administration in Statist France. In E. E. Otenyo, \& N. S. Lind (Eds.), Comparative public administration: the essential readings (pp. 741-758). Amsterdam, Netherlands: Elsevier.
Fisch, S. (2005). Origins and history of the international Institute of Administrative Sciences: from its beginnings to its reconstruction after World War II (1910-1944/47). In F. Rugge, \& M. Duggett (Eds.), IIAS/IISA. Administration and service (19302005) (pp. 35-60). Brussels, Belgium: IOS Press.

François, A. (1970). L'informatique etl'Administration: trois thémes de réflexion. International Review of Administrative Sciences, 36(1), 56-66.

Gant, G. F. (2006). The concept of development administration. In E. E. Otenyo, \& N. S. Lind (Eds.), Comparative public administration: the essential readings (pp. 257-285). Amsterdam, Netherlands: Elsevier.

Godchot, J. E. (1970). Formation permanente des cadres supérieurs de la fonction publique en

France. International Review of Administrative Sciences, 36(1), 18-21.

Gonçalves, J. M. (1972). O factor humano na reforma administrativa. Problemas do Espaço Português, 1972(87), 169-218.

Groves, R. T. (1974). The Colombian National Front and Administrative Reform. Administration \& Society, 6(3), 316-336.

Henares, J. (1961). Curso de Funcionarios directivos del Ministerio de la Gobernación (España). International Review of Administrative Sciences, 27(1), 55-58.

Hosch, L. (1964). The Public Administration Division of the United Nations: a brief history. International Review of Administrative Sciences, 30(3), 231-241.

Instituto Português de Ciências Administrativas. (1969-1973). Ciências Administrativas. Boletim do Instituto Português de Ciências Administrativas. Lisboa, Portugal: Autor.

International Institute of Administrative Sciences. (1958). Items of News. International Review of Administrative Sciences, 24(3), 406.

International Institute of Administrative Sciences. (1971). Chronicle of the Institute: IIAS, its Sections and Members. International Review of Administrative Sciences, 37(3), 441-459. 
Israel, T. (1957). Le perfectionnement aux Etats-Unis des fonctionnaires étrangers. International Review of Administrative Sciences, 23(1), VI-VIII.

Kickert, W. J M. (2006). Changing European States, changing Public Administration: expansion and diversification of Public Administration in the postwar Welfare State: the case of the Netherlands. In E. E. Otenyo, \& N. S. Lind (Eds.), Comparative public administration: the essential readings (pp. 793-810). Amsterdam, Netherlands: Elsevier.

Koch, E. (1967). Development of Public Administration in Denmark since I960. International Review of Administrative Sciences, 33(1), 1-8.

Laberge, E. P. (1960). El desarrollo de la Administración Pública en América Central desde la Segunda Guerra Mundial. International Review of Administrative Sciences, 26(2), 166-180.

Langrod, G. (1964). Le nouveau statut des fonctionnaires en Espagne. International Review of Administrative Sciences, 30(3), 263-271.

Meyer, P. (1960). The development of Public Administration in the Scandinavian countries since 1945. International Review of Administrative Sciences, 26(2), 135-146.

Organização das Nações Unidas. (1945). Carta das Nações Unidas. Nova York, NY: Autor.

Otenyo, E. E., \& Lind, N. S. (2006). Managing institutions through planning and decentralization. In E. E. Otenyo, \& N. S. Lind (Eds.), Comparative public administration: the essential readings (pp. 221230). Amsterdam, Netherlands: Elsevier.

Passos, M. L. (1991). Resistências e desfasamentos num processo de modernização e desenvolvimento. Os reformadores no governo de Marcello Caetano. Sociologia - Problemas e Práticas, 1991(10), 21-42.

Pereira, C. S. (2005). Portugal e as Nações Unidas. In C. Branco, \& F. P. Garcia (Coords.), Os portugueses nas Nações Unidas. Os 60 anos da ONU (pp. 143-162). Lisboa, Portugal: Prefácio.

Phillips, H. (1963). Development administration and the alliance for progress. International Review of Administrative Sciences, 29(1), 5-12.
Pozas, L. J. (1957). La organización y las ciencias administrativas en España. International Review of Administrative Sciences, 23(1), 1-16.

Rollo, M. F. (2007). Portugal e a reconstrução económica do pós-guerra. O Plano Marshall e a economia portuguesa dos anos 50 (Coleção Biblioteca Diplomática do MNE - Série D). Lisboa, Portugal: Ministério dos Negócios Estrangeiros.

Salgueiro, G. (1971). Para definição de uma política de pessoal na Administração Pública portuguesa. Boletim do Instituto Português de Ciências Administrativas, 1971(7), 5-55.

Secretariado da Reforma Administrativa. (1968). Principes et lignes directrices de la Réforme Administrative au Portugal. Lisboa, Portugal: Autor.

Talloen, L. (1957). Adiestramiento de funcionarios y asistencia técnica de las Naciones Unidas. International Review of Administrative Sciences, 23(4), 476.

United Nations Organization. (1948, December 4). International facilities for the promotion of training in public administration. Recuperado de https://www. refworld.org/docid/3b00f09238.html

United Nations Organization. (1951). Standards and techniques of public administration. with special reference to technical assistance for under-developed countries. Report by The Special Committee on Public Administration Problems. New York, NY: Author.

United Nations Organization. (1953). Resolução 492 (XVI) do Conselho Económico e Social. Resoluções da Assembleia Geral e do Conselho Económico e Social, 5-6. Recuperado de https://digitallibrary. un.org

United Nations Organization. (1967). United Nations Programme in Public Administration. Report of the Meeting of Experts. New York, NY: Author.

Uotila, J. (1961). Improving Public Administration in Finland. International Review of Administrative Sciences, 27(1), 65-70.

Wurmser, L. (1957). L'Automation dans le domaine $\mathrm{du}$ travail de bureau. International Review of Administrative Sciences, 23(1), 17-25. 
RAP | Reformar a Administração Pública no novo mundo saído da guerra. Projeto nacional ou dinâmica global? (1950-1970)

\section{Ana Carina Azevedo}

https://orcid.org/0000-0001-6632-6861

Doutora em História e investigadora do Instituto de História Contemporânea, Faculdade de Ciências Sociais e Humanas da Universidade Nova de Lisboa. E-mail: aazevedo@fcsh.unl.pt 